\title{
Herpes Zoster After Liver Transplantation: Incidence, Risk Factors, and Complications
}

\author{
J. Ignacio Herrero, ${ }^{1}$ Jorge Quiroga, ${ }^{1}$ Bruno Sangro, ${ }^{1}$ Fernando Pardo, ${ }^{2}$ \\ Fernando Rotellar, ${ }^{2}$ Javier Alvarez-Cienfuegos, ${ }^{2}$ and Jesus Prieto ${ }^{I}$
}

\begin{abstract}
Herpes zoster is the consequence of the reactivation of latent varicella-zoster infection. Immunosuppression may be a predisposing factor for herpes zoster. We have retrospectively assessed the risk of herpes zoster, the risk factors for its occurrence, and its evolution in a population of 209 consecutive liver transplant recipients. Herpes zoster developed in $25(12 \%)$ of patients. One-, 3-, 5-, and 10 -year actuarial rates of herpes zoster were $3 \%, 10 \%$, $14 \%$, and $18 \%$, respectively. In a case-control study, patients developing herpes zoster were younger, received a higher number of immunosuppressive drugs, and were more frequently receiving mycophenolate mofetil or azathioprine. In multivariate analysis, the only factor related to herpes zoster occurrence was treatment with mycophenolate mofetil or azathioprine. Eight patients (31\%) developed postherpetic neuralgia. In conclusion, herpes zoster is a relateively common complication after liver transplantation. It is related to immunosuppressive therapy. Postherpetic neuralgia develops in one third of patients with posttransplant herpes zoster. (Liver Transpl 2004;10:1140-1143.)
\end{abstract}

$\mathrm{L}$ atent varicella-zoster infection is almost universal in adult populations from Europe and North America. Reactivation causes herpes zoster (HZ), which appears as a painful cutaneous eruption with dermatomal distribution. The most frequent complication of $\mathrm{HZ}$ is postherpetic neuralgia (PHN), which may persist for months or even years.

The annual incidence of $\mathrm{HZ}$ in the general population is 1.5 to 3.0 cases per 1,000 persons. ${ }^{1}$ Posttransplant immunosuppression may increase this incidence. ${ }^{2}$

Several studies have evaluated the incidence of $\mathrm{HZ}$ after bone marrow transplantion and in patients with human immunodeficiency virus infection, but data on

Abbreviations: HZ, herpes zoster; PHN, postherpetic neuralgia; MMF, mycophenolate mofetil.

From the ${ }^{1}$ Liver Unit and ${ }^{2}$ Deparment of Surgery, Clinica Universitaria de Navarra, Pamplona, Spain.

Supported in part by grants from the Instituto de Salud Carlos III (CO2/03 and CO3/03) (J.I.H.).

Address reprint requests to J. Ignacio Herrero, Clinica Universitaria de Navarra, Liver Unit, Avda.Pio XII S/N, Pamplona, Spain. Telephone: 34948 296789; FAX: 34948 296500; E-mail: iherrero@unav.es

Copyright (c) 2004 by the American Association for the Study of Liver Diseases

Published online in Wiley InterScience (www.interscience.wiley.com). DOI 10.1002/lt.20219 liver transplant recipients are scarce. ${ }^{2,3}$ Therefore, we have performed a retrospective study to investigate the incidence, risk factors, and complications of $\mathrm{HZ}$ after liver transplantation.

\section{Patients and Methods}

We have performed a retrospective analysis of our prospectively collected database of all liver transplantations carried out in our center between April 1990 and June 2002. All patients were followed until December 2002. HZ was defined as the appearance of a cutaneous vesicular eruption with a dermatomal distribution. The location, distribution, extension, treatment, and complications of $\mathrm{HZ}$ were recorded. $\mathrm{PHN}$ was defined as pain in the area of the eruption persisting for more than 30 days after the rash. ${ }^{4}$

Immunosuppressive therapy has been described previously. ${ }^{5}$ Calcineurin inhibitors (cyclosporine or tacrolimus), azathioprine, and steroids were administered as primary immunosuppression. Long-term monotherapy based on calcineurin inhibitors was attempted. From 1996, calcineurin inhibitors were partially or completely switched to mycophenolate mofetil (MMF) in the case of renal insufficiency. ${ }^{6}$

Antiviral prophylaxis protocol included the administration of ganciclovir ( $5 \mathrm{mg} / \mathrm{kg} /$ day intravenously for 2 weeks) to patients who were cytomegalovirus negative before transplantation. Those patients with acute rejection who received steroid boluses and/or OKT3 received prophylaxis with oral acyclovir/ganciclovir for 4-8 weeks. Herpes simplex infection was treated with oral acyclovir for one week. Cytomegalovirus disease was treated with ganciclovir $(5 \mathrm{mg} / \mathrm{kg}$ b.i.d. intravenously for 2 weeks) followed by oral acyclovir for 2 months.

The actuarial incidence of $\mathrm{HZ}$ after liver transplantation was obtained by the Kaplan-Meier method. To assess which factors could predispose to $\mathrm{HZ}$, a case-control study was performed. Two controls were obtained for every case, namely patients who had been transplanted immediately before and after the case and were alive at the moment of the diagnosis of HZ. Controls were not matched by age, sex, disease severity, or cytomegalovirus status to make possible the study of these variables as potential risk factors of $\mathrm{HZ}$. The following data were obtained from cases and controls: age; sex; cause of liver transplantation; Child-Turcotte-Pugh status at transplantation; cytomegalovirus serology before transplantation; past history of rejection; antiviral therapy; and immunosuppression (induction immunosuppression with cyclosporine, cyclosporine microemulsion, or tacrolimus; current number of immunosuppressive drugs; current and cumulative doses of 


\begin{tabular}{|c|c|}
\hline \multicolumn{2}{|c|}{ Table 1. General Characteristics of the Patients } \\
\hline & No. of Patients \\
\hline Age at transplantation $(\mathrm{yr})^{*}$ & $55.5(9.87)$ \\
\hline Gender (male / female) & $153 / 56$ \\
\hline \multicolumn{2}{|l|}{ Cause of liver transplantation } \\
\hline Alcoholic cirrhosis & 76 \\
\hline Hepatitis C virus cirrhosis & 76 \\
\hline Hepatitis B virus cirrhosis & 14 \\
\hline Primary biliary cirrhosis & 10 \\
\hline Metabolic cirrhosis & 13 \\
\hline Other causes & 20 \\
\hline Hepatocellular carcinoma & 67 \\
\hline \multicolumn{2}{|l|}{ Child-Turcotte-Pugh stage } \\
\hline$(\mathrm{A} / \mathrm{B} / \mathrm{C})^{* *}$ & $27 / 98 / 78$ \\
\hline Acute rejection & 54 \\
\hline \multicolumn{2}{|l|}{ Calcineurin inhibitor } \\
\hline Cyclosporine & 95 \\
\hline Cyclosporine-Neoral & 33 \\
\hline Tacrolimus & 81 \\
\hline $\begin{array}{l}{ }^{*} \text { Value expressed as mean }(\mathrm{SD} \\
{ }^{* *} \text { Five patients without liver } \\
\text { fulminant hepatic failure were }\end{array}$ & $\begin{array}{l}\text { d one patient with } \\
\text { ed. }\end{array}$ \\
\hline
\end{tabular}

prednisone; current use of MMF or azathioprine; and current use of cyclosporine, tacrolimus, or none of them). The possible influence of renal insufficiency (defined as a creatinine level equal or above $1.5 \mathrm{mg} / \mathrm{dL}$ ) and diabetes mellitus (defined as the need for antidiabetic drugs) were also assessed at the moment of diagnosis of $\mathrm{HZ}$.

To compare both groups, chi-square and Mann-Whitney $\mathrm{U}$ tests were used for categorical or continuous variables, respectively. Multivariate analysis (logistic regression) was performed with those variables with $P<.1$ in univariate analysis.

\section{Results}

General characteristics of the patients are described in Table 1. Twenty-five patients (12\%) had HZ. The median time of onset of $\mathrm{HZ}$ was 23 months (range, 10 days to 90 months) after transplantation. Actuarial 1-, 3-, 5-, 7-, and 10-year incidences of $\mathrm{HZ}$ were 3\%, 10\%, $14 \%, 17 \%$, and $18 \%$, respectively (Fig. 1). In 12 of the cases $(48 \%)$, HZ eruption was located in the thorax. Other locations were neck and shoulder (3 cases), head (3 cases), abdomen ( 2 cases), and leg ( 5 cases). All were unilateral. In 5 cases (20\%), more than one dermatome was affected. In 4 cases (16\%), the eruption recurred after initial healing; two were early recurrences, and the other 2 had $\mathrm{HZ}$ recurrence several years after the first eruption. Eight patients (32\%) had PHN. In 5 of these patients, PHN resolved within 6 months, but the other 3 patients required pharmacological therapy for more

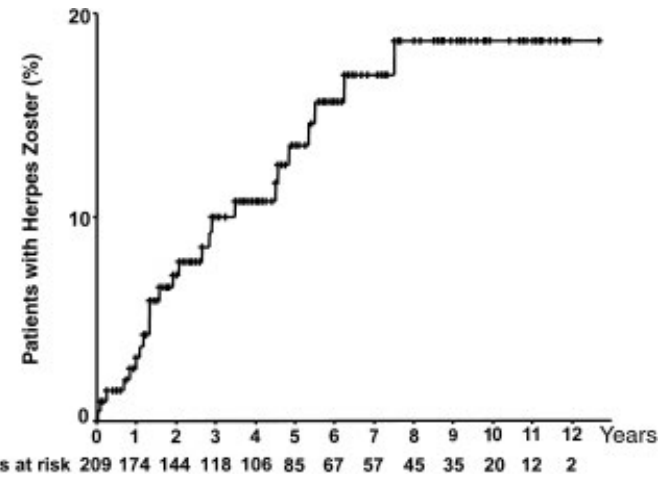

Figure 1. Actuarial incidence of herpes zoster after liver transplantation.

than 2 years. General characteristics of $\mathrm{HZ}$ episodes and antiviral therapy are shown in Table 2 .

Regarding therapy, 1 patient did not receive antivirals, 4 patients received intravenous acyclovir, 1 patient received intravenous ganciclovir, 5 patients received oral famciclovir, and 14 patients received oral acyclovir. The duration of antiviral therapy was less than or equal to 2 weeks in 19 patients. Four patients received antiviral treatment for 3-8 weeks, and 1 patient was treated for 3 months. There was no relation between the development of PHN and the antiviral drug used or the duration of therapy.

General characteristics of cases and controls are shown in Table 3. Patients with HZ were younger, received a higher number of immunosuppressive drugs, and were more frequently on treatment with azathioprine or MMF. In multivariate logistic regression analysis, the only factor related to $\mathrm{HZ}$ was treatment with azathioprine or MMF (hazard ratio, 4.20; 95\% confidence interval, 1.48-11.91; $P=.005)$.

Five of the 25 patients who had $\mathrm{HZ}$ had increases in

\begin{tabular}{|lc|}
\hline \multicolumn{2}{|l|}{ Table 2. General Characteristics of Herpes Zoster } \\
Episodes, Therapy, and Evolution \\
\hline \multicolumn{2}{|c|}{ Number of Patients } \\
Extension & 20 \\
One dermatome & 5 \\
More than one dermatome & \\
Complications & 4 \\
Recurrences & 8 \\
Postherpetic neuralgia & 1 \\
Antiviral therapy (median duration) & 4 (1 week) \\
None & 14 (2 weeks) \\
Acyclovir (intravenous) & 1 (2 weeks) \\
Acyclovir (oral) & 5 (one week) \\
Ganciclovir (intravenous) & \\
Famciclovir &
\end{tabular}




\begin{tabular}{|c|c|c|c|}
\hline & Cases $(\mathrm{N}=25)$ & Controls $(\mathrm{N}=50)$ & $P$ \\
\hline Age $(y r)^{*}$ & $55.7(6.24)$ & $57.5(10.7)$ & .076 \\
\hline Gender (male / female) & $16 / 9$ & $34 / 16$ & NS \\
\hline CMV negative & 0 & 3 & NS \\
\hline Indication of transplant & & & NS \\
\hline Alcoholic cirrhosis & 8 & 14 & \\
\hline HCV cirrhosis & 8 & 21 & \\
\hline HBV cirrhosis & 2 & 3 & \\
\hline Primary biliary cirrhosis & 3 & 2 & \\
\hline Metabolic cirrhosis & 1 & 3 & \\
\hline Hepatocellular carcinoma & 7 & 20 & NS \\
\hline Child-Turcotte-Pugh (A / B / C) & $2 / 11 / 11$ & $11 / 23 / 18$ & NS \\
\hline Initial immunosuppression & & & NS \\
\hline Cyclosporine & 12 & 26 & \\
\hline Cyclosporine Neoral & 6 & 12 & \\
\hline Tacrolimus & 7 & 12 & \\
\hline Actual immunosuppression & & & NS \\
\hline Cyclosporine & 16 & 31 & \\
\hline Tacrolimus & 9 & 18 & \\
\hline Number of immunosuppressive drugs* & $2.24(.18)$ & $1.76(.12)$ & .017 \\
\hline AZA or MMF & 18 & 19 & .007 \\
\hline Previous rejection & 10 & 18 & NS \\
\hline Antiviral therapy & & & NS \\
\hline No & 11 & 27 & \\
\hline Less than 4 weeks & 6 & 11 & \\
\hline More than 4 weeks & 7 & 10 & \\
\hline Diabetes mellitus & 3 & 10 & NS \\
\hline Renal insufficiency & 10 & 12 & NS \\
\hline
\end{tabular}

their immunosuppression in the 6 weeks preceeding HZ. The causes of these increases were corneal transplantation, retransplantation, treatment of recurrent autoimmune hepatitis, and change of therapy due to nephrotoxicity (association with MMF, and a switch from cyclosporine to tacrolimus). Only one of the 50 controls had an increase in their immunosuppressive therapy in the preceeding weeks.

\section{Discussion}

$\mathrm{HZ}$ is a consequence of the reactivation of latent infection by varicella-zoster virus. Our paper shows that $\mathrm{HZ}$ is not an infrequent complication of liver transplantation. In fact, the incidence of $\mathrm{HZ}$ in our series is higher than previously reported.2,3 This incidence is much higher than the incidence of $\mathrm{HZ}$ in the general population, ${ }^{7,8}$ and it seems to be comparable to the incidences of $\mathrm{HZ}$ found in other solid-organ-transplant recipients ${ }^{2}$ and in patients with human immunodeficiency virus infection ${ }^{9}$ but much lower than the incidence occurring after bone marrow transplantation. ${ }^{10}$

As previously observed, the use of antiviral prophylaxis does not seem to prevent the development of $\mathrm{HZ}$ after organ transplantation ${ }^{2}$ This finding in not surprising, as the onset of HZ following LT is relatively high, and antiviral prophylaxis is administered in the first few weeks after transplantation. In the same way, a past history of rejection was not related to the development of $\mathrm{HZ}$, as most episodes of rejection happen in the early posttransplant period. HZ seems to be more related to maintenance immunosuppression, because it happened a median of 2 years after transplantation. In this setting, an increase of immunosuppression may trigger the reactivation of HZ. In our series, $20 \%$ of $\mathrm{HZ}$ happened after recent increases of immunosuppression.

Development of $\mathrm{HZ}$ in liver transplant recipients is related to immunosuppressive therapy. In their paper, Gaurishankar et al. found that $\mathrm{HZ}$ was 4 times more 
frequent in patients receiving MMF than in patients receiving azathioprine. ${ }^{2}$ In our series, therapy with azathioprine or MMF was the only factor independently related to the occurrence of $\mathrm{HZ}$.

Despite an older age is a predisposing factor for $\mathrm{HZ}$ in the general population, in our series cases were not older than controls. In the posttransplant setting, the weight of immunosuppression as a predisposing factor for $\mathrm{HZ}$ may mask the potential effect of age. Furthermore, as younger patients have a higher risk of rejection ${ }^{11}$ they usually require a more powerful immunosuppression. In our series, most patients received antiviral therapy with oral acyclovir or famciclovir. This therapy was effective, but 2 patients had early recurrence of $\mathrm{HZ}$, shortly after primary healing. One of them did well with another 1-week course of oral acyclovir. The other received antiviral therapy for 3 months.

One of the most feared complications of $\mathrm{HZ}$ is PHN. In this series, one third of the patients had this complication, and for some of the patients with $\mathrm{PHN}$, pain persisted for years. This proportion is relatively high, but it is comparable to the proportion of $\mathrm{PHN}$ in immunocompetent patients older than 60 years. ${ }^{4}$ Fortunately, none of the patients in this series had any other more severe complication of $\mathrm{HZ}$, such as retinitis, visceral involvement, or other neurological complications. ${ }^{12}$

In conclusion, $\mathrm{HZ}$ is a frequent complication after liver transplantation. Its evolution is usually satisfactory with oral therapy, but PHN is a frequent complication. Patients receiving more intensive immunosuppression have a greater risk of developing $\mathrm{HZ}$.

\section{References}

1. Gnann JW, Whitley RJ. Herpes zoster. N Engl J Med 2002;347: $340-346$.

2. Gourishankar S, McDermid JC, Jhangri GS, Preiksaitis JK. Herpes zoster infection following solid organ transplantation: incidence, risk factors and outcomes in the current immunosuppressive era. Am J Transplant 2004;4:108-115.

3. Gnann JW. Other herpesviruses: Herpes simplex virus, varicellazoster virus, human herpes types 6, 7, and 8. In: Transplant Infections, 1st edition. Philadelphia, PA: Lippincott-Raven; 1998:265-286.

4. Kost RG, Strauss SE. Postherpetic neuralgia: Pathogenesis, treatment and prevention. N Engl J Med 1996;335:32-42.

5. Herrero JI, Lucena JF, Quiroga J, Sangro B, Pardo F, Rotellar F, et al. Liver transplant recipients older than 60 years have lower survival and higher incidence of malignancy. Am J Transplant 2003;3:1407-1412.

6. Herrero JI, Quiroga J, Sangro B, Girala M, Gomez-Manero N, Pardo F, et al. Conversion of liver transplant recipients on cyclosporine with renal impairment to mycophenolate mofetil. Liver Transpl Surg 1999;5:414-420.7. Donahue JG, Choo PW, Manson JE, Platt R. The incidence of herpes zoster. Arch Intern Med 1005;155:1605-1609.

8. Ragozzino MW, Melton LJ III, Kurland LT, Chu CP, Perry HO. Population-based study of herpes-zoster and its sequelae. Medicine (Baltimore) 1982;61:310-316.

9. Buchbinder SP, Katz MH, Hessol NA, Liu JY, O'Malley PM, Underwood R, Holmber SD. Herpes zoster and human immunodeficiency virus infection. J Infect Dis 1992;166:1153-1156.

10. Gomez-Manero N, Herrero JI, Quiroga J, Sangro B, Pardo F, Cienfuegos JA, Prieto J. Prognostic model for early acute rejection after liver transplantation. Liver Transpl 2001;7:246-254.

11. Gilden DH, Kleinschmidt-DeMaster BK, LaGuardia JJ, Mahalingam R, Cohrs RJ. Neurologic complications of the reactivation of varicella-zoster virus. N Engl J Med 2000;342:635645. 